\title{
Sliding-mode controller for a photovoltaic system based on a Ćuk converter
}

\author{
Carlos Andrés Ramos-Paja ${ }^{1}$, Daniel González-Motoya ${ }^{2}$, Juan Pablo Villegas-Ceballos ${ }^{3}$, Sergio Ignacio \\ Serna-Garcés ${ }^{4}$, Roberto Giral ${ }^{5}$ \\ ${ }^{1}$ Facultad de Minas, Universidad Nacional de Colombia, Colombia \\ ${ }^{2,3,4}$ Departamento de Electrónica y Telecomunicaciones, Instituto Tecnológico Metropolitano, Colombia \\ ${ }^{5}$ Departament d' Enginyeria Electrònica, Elèctrica i Automàtica, Universitat Rovira i Virgili, Spain
}

\begin{tabular}{|c|c|}
\hline Article Info & ABSTRACT \\
\hline Article history: & The wide range of step-up and step-down input-output voltage characteristic of the \\
\hline $\begin{array}{l}\text { Received Apr 24, } 2020 \\
\text { Revised Sep 19, } 2020 \\
\text { Accepted Oct 6, } 2020\end{array}$ & $\begin{array}{l}\text { Ćuk converter makes it a good candidate to interface photovoltaic arrays in both clas- } \\
\text { sical and distributed maximum power point tracking systems. Because its two inductor } \\
\text { structure, Ćuk converters have continuous input and output currents, which reduce the } \\
\text { additional filtering elements usually required for interfacing dc/dc converter topolo- } \\
\text { gies. However, PV systems based on Ćuk converters usually do not provide formal }\end{array}$ \\
\hline $\begin{array}{l}\text { Keywords: } \\
\text { Ćuk converter } \\
\text { Photovoltaic DMPPT } \\
\text { Sliding mode control } \\
\text { Wide range voltage }\end{array}$ & $\begin{array}{l}\text { proofs of global stability under realistic conditions, which makes impossible to en- } \\
\text { sure a safe operation of the PV installation. Therefore, this paper proposes a high- } \\
\text { performance sliding-mode controller for PV systems based on Cuk converters, which } \\
\text { regulates the PV voltage in agreement with the commands imposed by a MPPT algo- } \\
\text { rithm, rejecting both load and environmental perturbations, and ensuring global stabil- } \\
\text { ity for real operation conditions. Finally, the performance of the regulated PV system } \\
\text { is tested using both simulations and experiments. }\end{array}$ \\
\hline
\end{tabular}

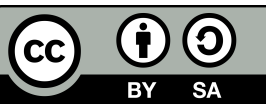

Corresponding Author:

Juan Pablo Villegas-Ceballos

Departamento de Electrónica y Telecomunicaciones

Instituto Tecnológico Metropolitano

Calle 73 No. 76A - 354, Medellín, Colombia

Email: juanvillegas@itm.edu.co

\section{INTRODUCTION}

The development of PV systems is an active topic due to the use of those generation systems in many types of electrical installations: i) large power plants [1], ii) small installations for both grid-tie and stand-alone applications [2-4], and iii) industrial installations. In some cases, it is necessary to connect the PV installation to the AC-grid and in other cases to stand alone loads or DC-buses. The first ones usually adopt step-up converters to match the low-voltage provided by the PV modules with the high-voltage required by commercial grid-connected inverters [5-10]. Instead, the second systems have more diverse requirements; for example, PV systems interacting with stand-alone AC loads usually adopt step-up converters [5, 11-13], but PV systems designed for battery charging or to interacting with DC loads often use step-down converters [14, 15]. Figure 1 depicts some of those types of PV systems: Type I uses a step-up dc/dc converter to perform the maximum power point tracking (MPPT) control on the PV source, which ensures the extraction of the maximum power from the PV string. Then, a dc/ac converter (inverter) injects such a PV power into the grid; in this type of PV system usually $v_{p v}<v_{d c}$. Type II has a similar structure, but the dc/ac converter interacts with an 
AC load, which requieres a different control algorithm for the inverter. Type III does not use dc/ac converters; instead, the step-down dc/dc converter interacts with a battery or DC load, hence $v_{p v}>v_{d c}$.

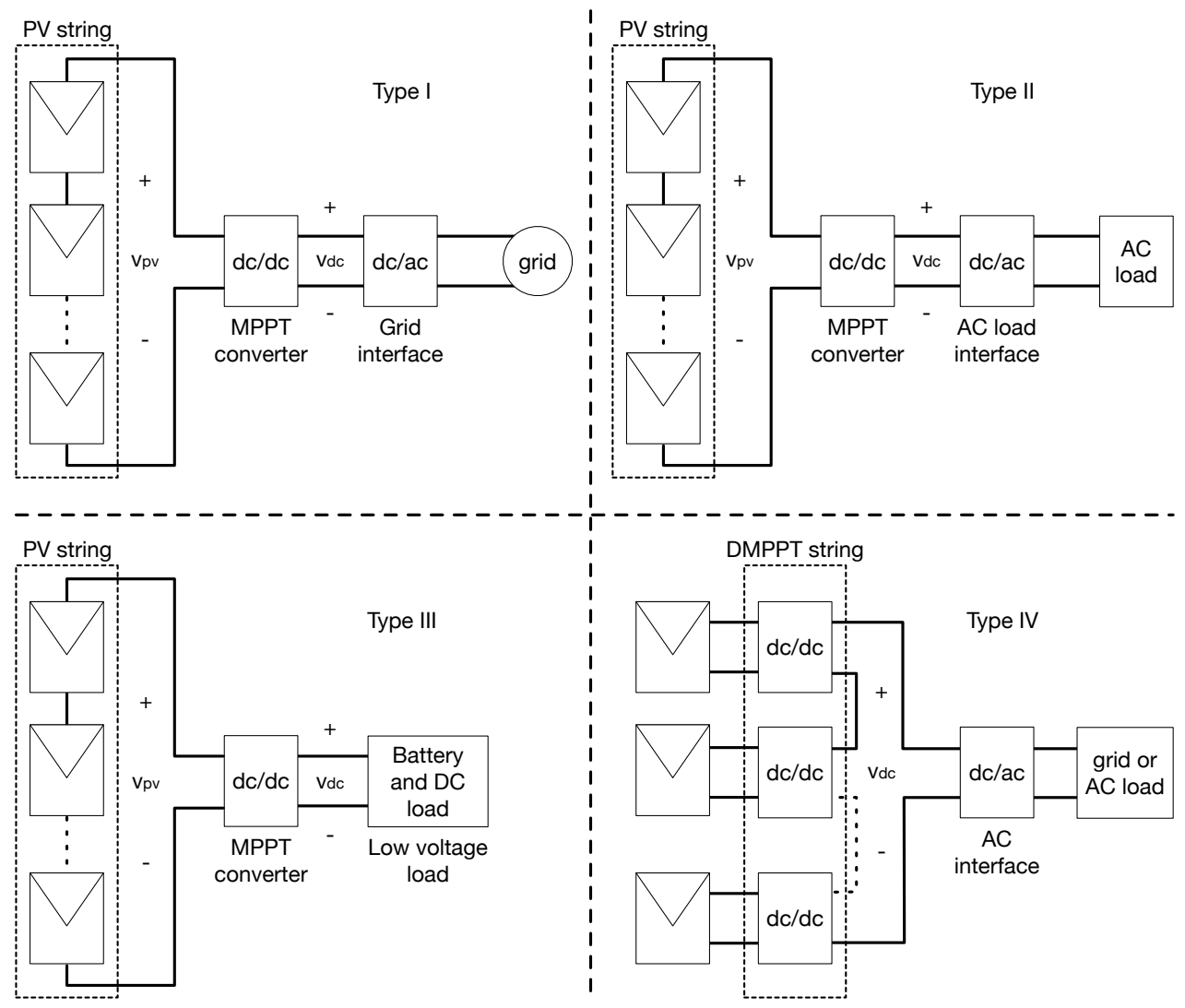

Figure 1. Types of PV systems

Moreover, there exists a novel PV system structure named distributed maximum power point tracking (DMPPT) [6, 16-18], which is designed to reduce the detrimental impact of the partial shading: such a phenomenon triggers the activation of the bypass diodes installed in commercial PV panels, which forces the shaded modules to operate at the second quadrant (with negative voltage); this condition produces a reduction in the power production and a health degradation on the shaded PV modules [13]. Those DMPPT systems have $\mathrm{dc} / \mathrm{dc}$ converters isolating each PV module, hence each PV module operates at the corresponding maximum power point (MPP) independent of the shading condition of the other modules. This type of PV system, depicted in Figure 1 as Type IV, exhibits a series-connection of the dc/dc converters outputs to produce the high voltage required by the dc/ac converter. Such a series-connection causes that the dc/dc converters must to share the voltage imposed at the input of the dc/ac converter. Therefore, with a low number of PV modules, each $\mathrm{dc} / \mathrm{dc}$ converter must support an output voltage higher than the input voltage, hence requiring a step-up voltage operation. Instead, with a high number of PV modules, each dc/dc converter must withstand an output voltage lower than the input voltage, hence requiring a step-down voltage operation. Finally, it is also possible that, for a particular number of PV modules, each dc/dc converter will exhibit the same voltage at both input and output terminals.

Therefore, PV systems require both step-up and step-down dc/dc converters depending on the application. Moreover, DMPPT systems require dc/dc converters able to support both step-up/down operation conditions. This type of problem has been addressed using the Ćuk converter [19-21], which can operate with output voltages lower, equal, or higher than the input voltage. Moreover, the Cuk converter provides continuous input and output current, which reduces the size of both the input and output filters required to provide high-quality power to the load. Those characteristics have made the Cuk converter a suitable option to design PV systems. For example, the works reported in [19, 21-25] propose PV systems based on Ćuk converters de- 
signed to supply resistive loads. However, such a design choice is not applicable to grid-connected systems, in which the converter load is the dc-link between the MPPT converter and the inverter. Another problem of those solutions is the lack of a capacitor between the PV module and the converter, hence all the switching ripple of the converter is propagated to the PV module, which produces additional power losses. Finally, the PV voltage is not regulated, which allows the propagation of the perturbations present at the dc-link into the PV module terminals. In contrast, in [23, 25] is adopted a MPPT fuzzy controller that could mitigate, in some degree, the effects of those perturbations, but formal stability analyses are not given, hence it is not a safe solution. A similar approach was proposed in [26], but the PV module is modeled as a voltage source, which significantly reduces the validity of the analyses; and similar to the previous cases, the PV voltage is not regulated, thus degrading the MPPT performance when perturbations occur [17].

A PV system with similar limitations was proposed in [27] for injecting power to the grid. As in the previous cases, the load of the Ćuk converter is considered as a constant resistance, which does not accurately represent the input impedance of an inverter. Moreover, the mathematical analyzes consider the PV module as a constant voltage source, which is a strong simplification. Therefore, both modeling considerations are not realistic enough for grid-connected systems. A similar approach was used in [28], where the load is considered as a constante resistance. In this case the PV module equations are described, but those expressions are not used in the Cuk converter analysis. Finally, such a paper does not considers any dynamic analysis or formal stability proof, hence it is not demonstrated the system safe operation.

A work representing the source and load of the Cuk converter with realistic models is reported in [29]. The system is formed by both wind and PV generators, and it is controlled with an MPPT based on an ant colony optimization algorithm and a fuzzy controller for a three-phase inverter. The MPPT operates at the Ćuk converter for tracking the maximum power point, but no formal analysis of the stability is provided. In fact, the Cuk converter is modeled with static equations without accounting for the dynamic behavior of the power system, which makes difficult to guarantee both the global stability of the system and the rejection of perturbations caused by the inverter or environmental conditions. On the other hand, the work reported in [30] improves the PV systems by controlling the Ćuk converter using a sliding-mode controller. Such a control approach provides fast dynamic responses and robustness to grid-connected perturbations. However, the mathematical analyses of that work adopt inaccurate models for both the load and the PV source: a resistive load and voltage source, respectively. Moreover, the conditions for global stability are not discussed.

The Ćuk converter has also been used for designing industrial PV applications, such as the water pumping systems reported in [31-33]. The devices developed in [31, 32] implement an incrementalconductance MPPT algorithm, but no formal regulation of the PV voltage is implemented. Therefore, the perturbations in the motor could spread to both the PV module and the MPPT controller. In [33], in addition to the above limitations, a fuzzy MPPT controller was designed considering a linearized model of the Ćuk converter, which makes difficult to guarantee the global stability of the system at multiple operation points.

The Ćuk converter has been also used for DMPPT applications with several limitations. For example, the work reported in [34] demonstrates the advantages, in terms of power production, of a DMPPT system based on Ćuk converters. However, such a work does not consider any control system to compensate the load perturbations, hence it is not evident that such a system will be stable under real operation condition. Similarly, the work reported in [35] proposed a DMPPT system with PI voltage controllers, which are unable to ensure global stability. Moreover, the PV module is represented by a Thevenin equivalent, hence the analyses are valid just at a given operating point. Finally, the work adopts a cascade MPPT algorithm based on the perturb-andobserve $(\mathrm{P} \& \mathrm{O})$ algorithm. Another DMPPT approach, based on the current equalization technique, is proposed in $[36,37]$. The main disadvantage of such a technique is the lack of voltage conversion ratio, since the string voltage is imposed by the MPP voltage of the modules. The work in [36] adopts a classical programmed current control, while the work in [37] does not consider any formal controller. Therefore, both approaches are not robust to perturbations generated by a grid-connected inverter.

In terms of PV systems control, Ćuk converters have been regulated using both linear and non-linear techniques. That is the case of the Cuk converter used for the micro-inverter reported in [38], which adopts a PI controller and a cascade MPPT algorithm. However, in that work the load is modeled with a constant impedance, which is not accurate to represent a grid-connected power system. Another approach was presented in [39], which uses the jump-parameter linear-optimal-control technique to regulate the Ćuk converter. Unfortunately, as in the previous cases, the load and PV model are simplified to a resistance and voltage source, respectively. PV systems based on Ćuk converters have been also controlled using more complex control tech- 
niques, such as the model predictive controller reported in [40]. The main problems of such a solution are the inaccurate PV source model (constant voltage) and the particular load model (constant resistance), which are not realistic for practical applications. Moreover, the is not a formal stability analysis, hence a safe operation is not demonstrated. in literature:

In conclusion, the following problems are present in the PV systems based on Ćuk converters reported

- Some solutions adopt non-realistic PV source and load models for the converter analysis, hence the system performance and stability are not ensured

- Other solutions do not consider the converter regulation using a high-bandwidth controllers able to mitigate perturbations. Therefore, load perturbations occurring in grid-conned PV systems [41] and DMPPT systems $[17,13]$ will be transferred to the source terminals, which could lead the MPPT controller to an unstable and dangerous operation [42]

- The solutions accounting for high-bandwidth controllers do not provide a global stability proof. Some of those solutions are based on linear controllers, which are not able to ensure the same performance and stability in all the operation range [43, 44], other solutions do not provide any stability analysis. Therefore, no stable and safe operation is ensured

This paper provides a solution solving all those problems, a non-linear controller ensuring global stability in all the operation range of the Ćuk based PV system, which is aimed at rejecting both the load and environmental perturbations to ensure a stable and safe operation. Such a controller is designed using realistic PV source and load models for the converter analysis, which ensures the solution applicability to stand-alone, grid-connected and DMPPT PV systems. The proposed converter analysis takes into account the effect of the non-linear behavior of the PV panel into the PV system, and the adopted load model is in agreement with the electrical behavior of a capacitive dc-link regulated by an additional device. The proposed controller is based on the sliding-mode theory, which has been successfully used [43] to develop a non-linear controller for a PV system based on a boost converter. Finally, the transversality, reachability and equivalent control conditions of the sliding-mode controller are analyzed in detail to provide a global stability proof. The remain of the paper is organized as follows: Section 2 presents the analysis of the PV system and the design of the proposed sliding-mode controller, describing also the stability conditions. Section 3 presents the performance evaluation of the system, under realistic conditions, using detailed circuital simulations. Then, section 4 presents the experimental validation of the solution using a proof-of-concept prototype. Finally, the conclusions of the work close the paper.

\section{DESIGN OF THE PROPOSED SLIDING-MODE CONTROLLER}

The circuital scheme of the PV system based on the Ćuk converter is presented in Figure 2. Such a scheme considers the PV string lumped into a single PV model scaled in current, which is a widely adopted model [44]. This modeling strategy enables to generalize the system analysis for any size of the PV array, i.e. large arrays used in PV systems Type I, II and III or the single modules used in PV systems Type IV.

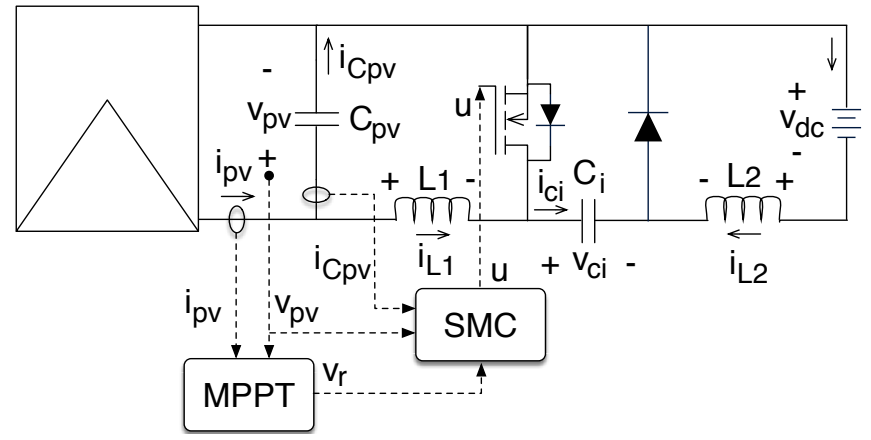

Figure 2. Circuital scheme of the PV system based on a Ćuk converter

The model also considers the output voltage $v_{d c}$ regulated by an external device: in systems Type I, II and IV the grid-connected inverter usually regulates the dc voltage $v_{d c}$ at the input terminals [17, 44], while 
in systems Type III the battery imposes the $v_{d c}$ voltage $[14,43]$. The Ćuk converter provides inverse polarities to the input terminals with respect to the output voltage, hence the PV string (or module) is connected as it is shown in Figure 2.

\subsection{Mathematical model of the PV system}

The Cuk converter is controlled using a binary signal $u$, which defines the state of the MOSFET ( $u=1$ is closed and $u=0$ is open; its complementary signal is $\bar{u}=1-u$ ). The signal $u$ is generated by a sliding-mode controller (SMC), which follows the command $v_{r}$ provided by a MPPT controller. In this cascade structure the MPPT controller defines the optimal PV voltage needed to extract the MPP power from the PV source, while the SMC ensures the stable operation of the PV system in such an optimal PV voltage, rejecting also perturbations. Applying the flux balance principle in the inductors and the charge balance principle in the capacitors [45], switched differential equations are obtained is being as (1)-(4):

$$
\begin{gathered}
C_{p v} \frac{d v_{p v}}{d t}=i_{p v}-i_{L 1} \\
C_{i} \frac{d v_{c i}}{d t}=i_{L 1} \cdot \bar{u}-i_{L 2} \cdot u \\
L_{1} \frac{d i_{L 1}}{d t}=v_{p v}-v_{c i} \cdot \bar{u} \\
L_{2} \frac{d i_{L 2}}{d t}=v_{c i} \cdot u-v_{b}
\end{gathered}
$$

Then, the averaged differential equations are obtained by averaging the switched equations within the switched period [45] is being as (5)-(8):

$$
\begin{gathered}
C_{p v} \frac{d v_{p v}}{d t}=i_{p v}-i_{L 1} \\
C_{i} \frac{d v_{c i}}{d t}=i_{L 1} \cdot(1-d)-i_{L 2} \cdot d \\
L_{1} \frac{d i_{L 1}}{d t}=v_{p v}-v_{c i} \cdot(1-d) \\
L_{2} \frac{d i_{L 2}}{d t}=v_{c i} \cdot d-v_{b}
\end{gathered}
$$

In the previous equations $d$ represents the duty-cycle of the converter. Finally, by applying the steadystate analysis of dc/dc converters [45], i.e. considering the derivatives of (5)-(8) equal to zero, static expressions are obtained as being as (9)-(12):

$$
\begin{gathered}
I_{p v}=I_{L 1} \\
I_{L 1}=I_{L 2} \cdot \frac{D}{(1-D)} \\
V_{c i}=\frac{V_{p v}}{(1-D)} \\
V_{c i}=\frac{V_{b}}{D}
\end{gathered}
$$

The previous equations use capital variables to represent steady-state values. 


\subsection{Controller surface and stability}

The main objective of the sliding-mode controller (SMC) is to impose the PV voltage value defined by the MPPT controller $[41,44,46]$. Therefore, the SMC must to drive the Cuk semiconductors to reject the perturbations generated by both the load and the environmental conditions. This paper proposes the switching function $\psi$ and the sliding surface $\phi$ given in (13) and (14), respectively.

$$
\begin{gathered}
\psi=K \cdot\left(v_{p v}-v_{r}\right)-i_{C_{p v}} \\
\phi=\{\psi=0\}
\end{gathered}
$$

In (13), $K$ is a constant that must be designed to impose the desired dynamic behavior to the PV voltage. Moreover, $i_{C_{p v}}$ represents the current of the capacitor $C_{p v}$ that defines the PV voltage, while $v_{r}$ is the reference imposed by the MPPT controller. To ensure both the viability and stability of the sliding surface (14) it is needed to perform two tests [17], transversality condition and reachability conditions. It must be noted that the equivalent control condition, in the context of dc/dc converters, is equivalent to the reachability conditions as it was demonstrated by Sira-Ramirez in [17].

The previous analyses require the derivative of the switching function (13) is being as (15):

$$
\frac{d \psi}{d t}=K \cdot \frac{d v_{p v}}{d t}-\frac{d i_{p v}}{d t}+\frac{d i_{L 1}}{d t}-K \cdot \frac{d v_{r}}{d t}
$$

Such a derivative takes into account that $i_{C_{p v}}=i_{p v}-i_{L 1}$. Then, replacing the differential (1) and (3) into (15) leads to the explicit expression given in (16).

$$
\frac{d \psi}{d t}=K \cdot \frac{i_{p v}-i_{L 1}}{d t}-\frac{d i_{p v}}{d t}+\frac{v_{p v}-v_{c i} \cdot \bar{u}}{L_{1}}-K \cdot \frac{d v_{r}}{d t}
$$

The derivatives of both PV current $\frac{d i_{p v}}{d t}$ and reference voltage $\frac{d v_{r}}{d t}$ are discussed afterwards.

\subsubsection{Transversality condition}

The transversality condition verifies the presence of the control signal $u$ into the switching function derivative, which is needed to modify the trajectory of the system state-variables. The mathematical representation of this condition is given in (17).

$$
\frac{d}{d u}\left(\frac{d \psi}{d t}\right) \neq 0
$$

Replacing expression (16) into (17) leads to expression (18):

$$
\frac{d}{d u}\left(\frac{d \psi}{d t}\right)=\frac{v_{c i}}{L_{1}}>0
$$

Since both $v_{c i}$ and $L_{1}$ are always positive, as it is demonstrated in (12), the proposed SMC fulfills the transversality condition.

\subsubsection{Reachability conditions}

The reachability conditions verify the capability of the SMC to converge into the desired sliding surface (14). The reachability conditions are the following ones: i) if the system operates under the surface, the switching function derivative must be positive to reach the surface; and ii) if the system operates above the surface, the switching function derivative must be negative to reach the surface [17]. Moreover, the sign of the transversality condition also affects the reachability conditions: a positive transversality value implies that $u=1$ produces a positive value of $\frac{d \psi}{d t}$; while a negative transversality value implies that $u=1$ produces a negative value of $\frac{d \psi}{d t}$ [17]. Therefore, taking into account that (18) is a positive value, the following reachability conditions must be fulfilled: 


$$
\begin{aligned}
& \left.\lim _{\psi \rightarrow 0^{-}} \frac{d \psi}{d t}\right|_{u=1}>0 \\
& \left.\lim _{\psi \rightarrow 0^{+}} \frac{d \psi}{d t}\right|_{u=0}<0
\end{aligned}
$$

Replacing (16) into (19) leads to:

$$
K \cdot \frac{i_{p v}-i_{L 1}}{C_{p v}}-\frac{d i_{p v}}{d t}+\frac{v_{p v}}{L_{1}}-K \cdot \frac{d v_{r}}{d t}>0
$$

However, the small-ripple approximation principle [45] establishes that the capacitor current, in a second-order filter, corresponds to the current ripple in the inductor. Examining the circuital scheme of Figure 2 reveals that the node connecting the PV source, the capacitor $C_{p v}$ and the inductor $L_{1}$ form a second order filter. This is verified by (9), which confirms that the steady-state current of both the PV source and the inductor $L_{1}$ are equal, hence the steady-state value of $C_{p v}$ current is cero. Therefore, the only component present into the current of $C_{p v}$ is the ripple of $L_{1}$.

Under the light of the previous analysis, the $C_{p v}$ current is given in (22), where $\delta i_{L 1}(t)$ is the timevarying current ripple in $L_{1}$. The maximum and minimum values of $\delta i_{L 1}(t)$ correspond to the current ripple magnitude in $L_{1}$, which is denoted by $\Delta i_{L 1}$.

$$
\left.\begin{array}{c}
i_{C_{p v}}=i_{p v}-i_{L 1}=\delta i_{L 1}(t) \\
-\Delta i_{L 1}<\delta i_{L 1}(t)<\Delta i_{L 1}
\end{array}\right\}
$$

Finally, expression (21) is modified by considering that $i_{C_{p v}}=i_{p v}-i_{L 1}$, replacing also the value obtained in (22) for $i_{C_{p v}}$, to define a first limitation on $\frac{d v_{r}}{d t}$ :

$$
\frac{d v_{r}}{d t}>\frac{-1}{K} \cdot\left(\frac{d i_{p v}}{d t}-\frac{v_{p v}}{L_{1}}-K \cdot \frac{\delta i_{L 1}}{C_{p v}}\right)
$$

Therefore, $\frac{d v_{r}}{d t}$ must to fulfill expression (23) to guarantee the surface reachability. The evaluation of such a limit must be performed at the worst-case conditions, i.e. the most restrictive values:

$$
\left.\begin{array}{c}
\frac{d i_{p v}}{d t}=\max \left(\frac{d i_{p v}}{d t}\right)>0 \\
\delta i_{L 1}=\max \left(\delta i_{L 1}\right)=\Delta i_{L 1}>0
\end{array}\right\}
$$

Similarly, the second reachability condition must be also analyzed. For that case, expression (16) is replaced into (20) is being as (25):

$$
K \cdot \frac{i_{p v}-i_{L 1}}{C_{p v}}-\frac{d i_{p v}}{d t}+\frac{v_{p v}-v_{c i}}{L_{1}}-K \cdot \frac{d v_{r}}{d t}>0
$$

Expression (24) is also modified by considering that $i_{C_{p v}}=i_{p v}-i_{L 1}$ and the $i_{C_{p v}}$ value given in (22) is being as (26):

$$
\frac{d v_{r}}{d t}<\frac{-1}{K} \cdot\left(\frac{d i_{p v}}{d t}-\frac{v_{p v}-v_{c i}}{L_{1}}-K \cdot \frac{\delta i_{L 1}}{C_{p v}}\right)
$$

Then, $\frac{d v_{r}}{d t}$ must to also fulfill expression (26) to guarantee the surface reachability. The evaluation of such a second limit must be performed at the worst-case conditions, i.e. the most restrictive values:

$$
\left.\begin{array}{c}
\frac{d i_{p v}}{d t}=\min \left(\frac{d i_{p v}}{d t}\right)<0 \\
\delta i_{L 1}=\min \left(\delta i_{L 1}\right)=-\Delta i_{L 1}<0
\end{array}\right\}
$$


In conclusion, the reference signal provided by the MPPT algorithm must to fulfill the dynamic restrictions given by (23)-(24) and (26)-(27) to ensure the reachability conditions. In practice, those dynamic restrictions correspond to a slew-rate limitation of the reference signal.

\subsubsection{Closed-loop dynamics}

In dc/dc converter applications, the stability of a SMC is ensured by both the transversality and reachability conditions; this taking into account that the equivalent control condition is equivalent to both reachability conditions [17]. Such stability ensures the existence of the sliding-mode, which imposes a system trajectory parallel to the surface and with a null steady-state error [17]. Those conditions are formalized is being as (28):

$$
\left\{\psi=0, \frac{d \psi}{d t}=0\right\}
$$

The previous conditions correspond to the closed-loop behavior of the PV system under the action of the SMC. Replacing expressions (1) and (13) into $\psi=0$, and taking into account that $C_{p v} \frac{d v_{p v}}{d t}=i_{C_{p v}}=$ $i_{p v}-i_{p v}$, the closed-loop expression is obtained is being as (29):

$$
\frac{d v_{p v}}{d t}=\frac{K}{C_{p v}} \cdot\left(v_{p v}-v_{r}\right)
$$

Such an expression defines the closed-loop behavior of the PV voltage. Therefore, (29) is used in the following section to calculate a value of $K$ that imposes the desired behavior to the PV system.

\subsection{Design of the dynamic response}

Expression (29) put into evidence that the closed-loop behavior of the PV voltage is equivalent to a linear system. Hence, expression (29) is analyzed in Laplace domain as being as (30):

$$
\frac{v_{p v}(s)}{v_{r}(s)}=\frac{1}{1-\frac{C_{p v}}{K} \cdot s}
$$

The most commonly used MPPT algorithm for PV systems is the perturb and observe (P\&O) solution [13], which produces step-like changes on the PV voltage to track the optimal value that maximizes the power production. The $\mathrm{P} \& \mathrm{O}$ is characterized by two parameters: the perturbation size $\Delta_{p o}$ and period $T_{a}$. Therefore, the dynamic response of the PV voltage corresponds to a first-order step response, in which the step magnitude is equal to $\Delta_{p o}$ :

$$
v_{p v}(s)=\Delta_{p o}\left(\frac{1}{s}-\frac{1}{s-\frac{K}{C_{p v}}}\right)
$$

From the previous expression it is noted that a stable (negative) pole is obtained only for negative values of $K$. Hence, the restriction must be fulfilled as being as (32):

$$
K<0
$$

Translating expression (31) to the time domain:

$$
v_{p v}=\Delta_{p o}\left(1-e^{\frac{K}{C_{p v}} \cdot t}\right)
$$

Then, expression (33) describes the closed-loop behavior of the PV voltage under the action of both the SMC and the P\&O algorithm. However, the P\&O requires a stable PV power to detect the best direction of the next perturbation, as it is explained in [13]. This means that the perturbation period $T_{a}$ must be longer than the settling-time $t_{s}$ of the PV system, otherwise the P\&O controller will be unstable; such an analysis can be found in [13]: 


$$
T_{a}>t_{s}
$$

Therefore, $K$ must be designed to ensure that condition (34) is fulfilled. This is done by calculating the settling time of the PV voltage from (33), which is given in (35) for the classical band of $2 \%$ :

$$
t_{s}=4 \cdot\left(-\frac{C_{p v}}{K}\right)
$$

Finally, replacing (35) into (34) gives:

$$
K \leq-\frac{4 \cdot C_{p v}}{T_{a}}
$$

In conclusion, $K$ must to fulfill the limit imposed by (36) to ensure a stable PV system. However, the value of $K$ could be tuned to reduce the settling-time of the PV system, which eventually makes possible to reduce the $\mathrm{P} \& \mathrm{O}$ period, hence providing a faster tracking of the optimal PV voltage.

\subsection{Practical implementation}

Theoretical SMCs impose infinite switching frequency [14], which could destroy the semiconductor devices. Therefore, SMCs for $\mathrm{dc} / \mathrm{dc}$ converters are implemented using hysteresis comparators to limit the switching frequency [14]. The hysteresis band $\pm H$ is placed around the desired value of the proposed slidingsurface to limit the switching frequency, which transforms (14) is being as (37):

$$
\phi=\{|\psi|<H\}
$$

Considering the reachability conditions given in (19) and (20), the control law needed to drive the system into the hysteresis band is being as (38):

$$
\left.\begin{array}{lll}
u=1 & \text { if } & \psi<-H \\
u=0 & \text { if } & \psi>+H
\end{array}\right\}
$$

The switching circuit designed to implement the control law given in (38) is depicted in Figure 3, which is based on two comparators and a Set-Reset Flip-Flop. In addition, Figure 3 also presents the calculation of the switching function $\psi$ from the measured variables: the PV voltage and $C_{p v}$ current. Finally, the figure also depicts the digital implementation of both the P\&O algorithm and the slew-rate limitation (SR) for the voltage reference, which is needed to fulfill the reachability conditions (23)-(24) and (26)-(27).

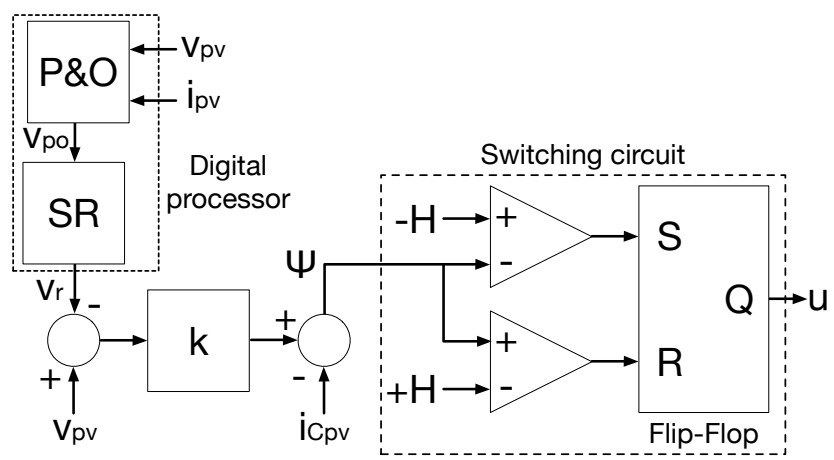

Figure 3. Implementation of the SMC

Moreover, from expressions (13) and (37) it is noted that $-H<\psi<H$, which corresponds to $-H<K \cdot\left(v_{p v}-v_{r}\right)-i_{C_{p v}}<H$. However, under a correct operation of the SMC, the PV voltage is equal to the reference value, i.e. $v_{p v}=v_{r}$, which leads to practical condition is being as (39): 


$$
-H<i_{C_{p v}}=\delta i_{L 1}(t)<H
$$

Finally, in section 2.2.2 the maximum and minimum values of $\delta i_{L 1}(t)$ where calculated as $\Delta i_{L 1}$ and $-\Delta i_{L 1}$, respectively. But expression (39) also reports the maximum and minimum values of $\delta i_{L 1}(t)$, which corresponds to $-H$ and $H$, respectively. Therefore, the magnitude of the current ripple in the inductor $L_{1}$ (and capacitor $C_{p v}$ ) is equal to $H$, and the limit values of $\delta i_{L 1}(t)$ are:

$$
\left.\begin{array}{c}
\min \left(\delta i_{L 1}\right)=-\Delta i_{L 1}=-H \\
\max \left(\delta i_{L 1}\right)=\Delta i_{L 1}=H
\end{array}\right\}
$$

In practice, the switching circuit can be implemented using a TS-555 integrated circuit as it is described in [14], or using the integrated circuit $C D 4043 N$ as it will be presented in section 4. Similarly, the calculation of $\psi$ could be implemented with operational amplifiers, digital processors, or with a combination of both circuits. Finally, the slew-rate limitation and $\mathrm{P} \& \mathrm{O}$ algorithm can be integrated into a single program inside a digital microprocessor as it is reported in [14].

\section{RESULTS AND DISCUSSION}

To test the performance of the proposed SMC, the following parameters are considered: $C_{p v}=C_{i}=$ $44 \mu \mathrm{F}, L_{1}=L_{2}=100 \mu \mathrm{H}, v_{b}=18 \mathrm{~V}$. Moreover, $H=500 \mathrm{~mA}$ was selected to ensure a maximum switching frequency equal to $85 \mathrm{kHz}$. The PV system considers a BP585 PV panel [17] as PV source, which is modeled using the ideal single diode model given in (41) [44], where $S$ represents the solar irradiance measured in $W / m^{2}$, with the following parameters: $A=896.8 n A, B=0.7029 V^{-1}$ and $k_{s}=(5 / 1000) A /\left(W / m^{2}\right)$.

$$
i_{p v}=i_{s c}-A \cdot e^{B \cdot v_{p v}}, i_{s c}=k_{s} \cdot S
$$

Figure 4 presents the polarization and power curves of the BP585 PV panel under five different irradiance conditions. The figure also depicts the MPP at each irradiance value. Such data put into evidence the requirement of using a MPPT algorithm to track the MPP under time-varying environmental conditions. As described before, this paper adopts the P\&O algorithm, which parameters were calculated following the procedure proposed in [17], obtaining $T_{a}=1 \mathrm{~ms}$ and $\Delta_{p o}=0.3 \mathrm{~V}$.
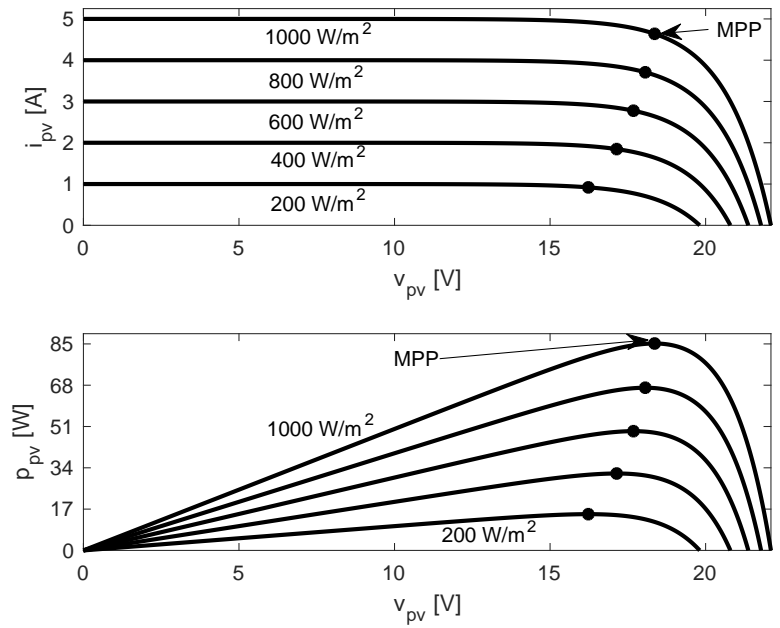

Figure 4. Polarization and power curves of the BP585 PV panel

The first step, for the PV system design, is to apply (35)-(37) to impose a settling-time $t_{s}$ equal to $500 \mu \mathrm{s}$, which is shorter than $T_{a}$, obtaining $K=-352 \mathrm{~mA} / \mathrm{V}$. Moreover, to test the dynamic restrictions 
given by (23)-(24) and (26)-(27), it is considered a maximum variation in the irradiance equal to 1 sun per millisecond: this corresponds to a transition from the maximum irradiance possible $\left(1 \mathrm{~kW} / \mathrm{m}^{2}\right)$ to a total shade within $1 \mathrm{~ms}$. Such a transition is translated into a change in the PV current from $5 A$ to $0 A$ within $1 \mathrm{~ms}$, hence:

$$
\left.\begin{array}{l}
\min \left(\frac{d i_{p v}}{d t}\right)=-5 \mathrm{kA} / \mathrm{s} \\
\max \left(\frac{d i_{p v}}{d t}\right)=+5 \mathrm{kA} / \mathrm{s}
\end{array}\right\}
$$

In addition, from (41) it is calculated that $\Delta i_{L 1}=500 \mathrm{~mA}$. Based on that value, and the ones given in (42), the maximum and minimum slew-rates for $v_{r}$, calculated from (23)-(24) and (26)-(27), are:

$$
-0.4858 \mathrm{~V} / \mu \mathrm{s}<\frac{d v_{r}}{d t}<0.4858 \mathrm{~V} / \mu \mathrm{s}
$$

Such a restriction is imposed using a voltage slew-rate limiter with a maximum derivative lower than $0.4858 \mathrm{~V} / \mu \mathrm{s}$. This functional block is usually implemented inside the microprocessor executing the $\mathrm{P} \& \mathrm{O}$ algorithm, as it was discussed in the previous section. For the simulations performed in this section, the maximum slew-rate of $v_{r}$ was set equal to $0.4850 \mathrm{~V} / \mu \mathrm{s}$, which ensures that the reachability conditions are fulfilled. Figure 5 presents the circuital simulation of the PV system, under the action of both the P\&O and SMC, for two different irradiance conditions: $1000 \mathrm{~W} / \mathrm{m}^{2}$ and $400 \mathrm{~W} / \mathrm{m}^{2}$.
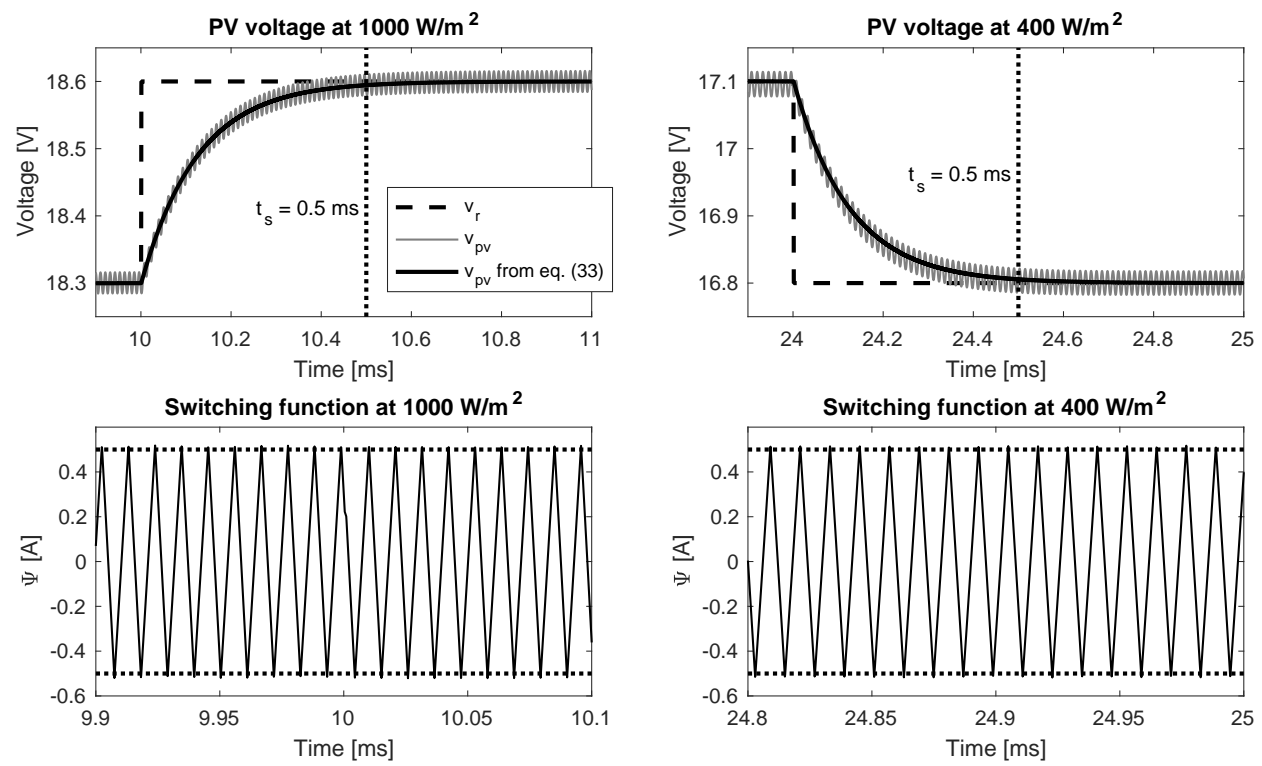

Figure 5. Dynamic response of the PV voltage

In the first case (top-left) the P\&O imposes a positive change on the PV voltage reference $v_{r}$, which is successfully tracked by the PV voltage $v_{p v}$ under the desired settling time $t s=500 \mu s$. The figure (top-left) also depicts the theoretical PV voltage waveform predicted by (33), which puts into evidence the correctness of the sliding-mode analysis and design. The figure at the bottom-left presents the switching function of the SMC operating at $1000 \mathrm{~W} / \mathrm{m}^{2}$, which is constrained inside the hysteresis band of $\pm 500 \mathrm{~mA}$. Such a condition verifies that the SMC exhibits a stable operation. In the second case (top-right), the P\&O imposes a negative change on $v_{r}$, which is again successfully tracked by $v_{p v}$ under the desired $t_{s}=500 \mu \mathrm{s}$. The figure at the bottom-right presents the switching function of the SMC at $400 \mathrm{~W} / \mathrm{m}^{2}$, which again is constrained inside the $\pm 500 \mathrm{~mA}$ hysteresis band. Therefore, the simulations reported in Figure 5 verify the stability of the SMC under both dynamic and static conditions. Moreover, the simulation also verifies the correctness of the design 
equations, and the ability of the SMC to impose the same dynamic performance to the PV voltage under different irradiance conditions.

Figure 6 presents another simulation of the PV system, which considers changes on the irradiance conditions: the irradiance reaching the $B P 585$ changes from $1000 \mathrm{~W} / \mathrm{m}^{2}$ to $400 \mathrm{~W} / \mathrm{m}^{2}$ at $13 \mathrm{~ms}$. The PV voltage exhibits the classical three-point behavior that ensures a stable operation of the $\mathrm{P} \& \mathrm{O}$ algorithm, hence it reports that the PV system operates at the MPP. In fact, Figure 4 confirms that the MPP power of the $B P 585$ is equal to $85.17 \mathrm{~W}$ at $1000 \mathrm{~W} / \mathrm{m}^{2}$ and $31.66 \mathrm{~W}$ at $400 \mathrm{~W} / \mathrm{m}^{2}$. Hence, the simulation results reported in Figure 6 validates the design of both the P\&O algorithm and SMC.
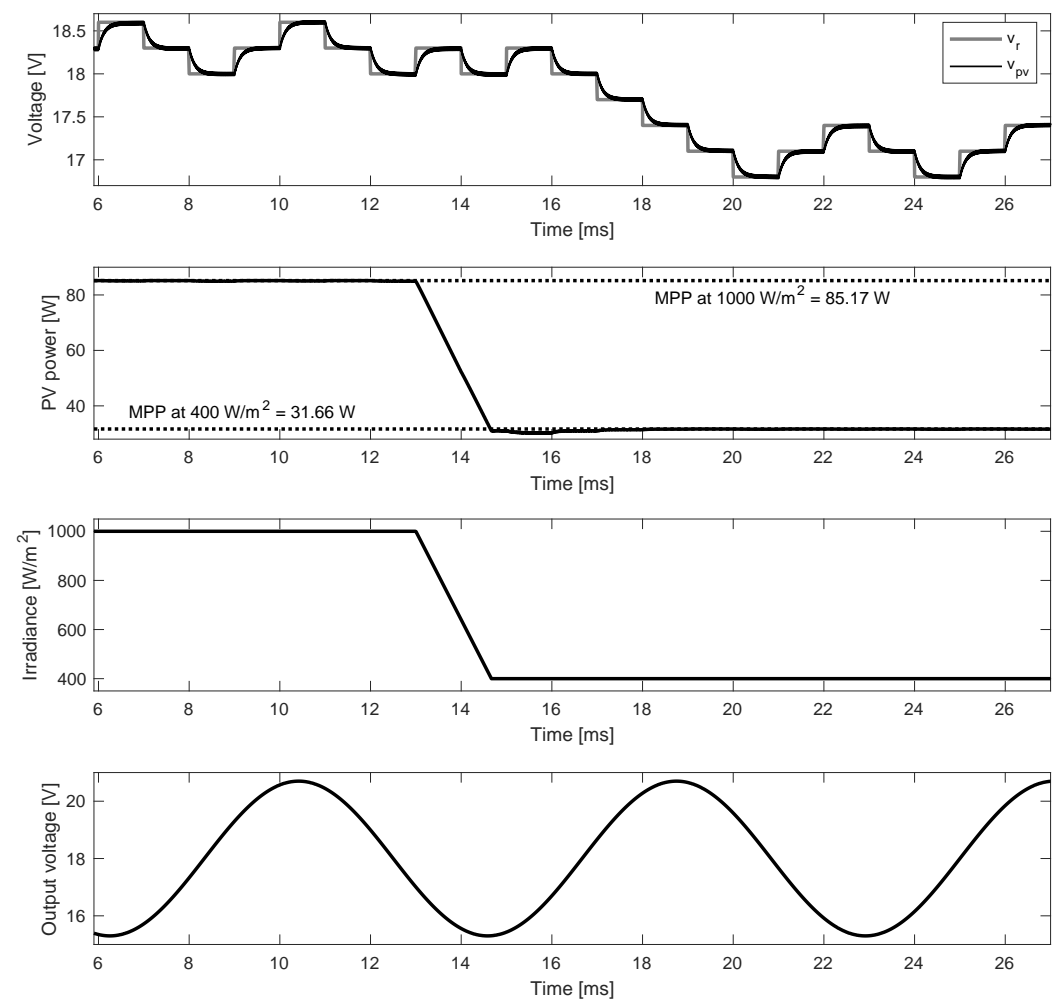

Figure 6. PV system performance under irradiance changes

In addition, that simulation also considers a sinusoidal perturbation at the de/dc converter output terminals. Such a perturbation is present in any PV system featuring an inverter connection, which is caused by the difference between the DC power extracted from the PV source and the AC power injected by the inverter; further details of such a phenomenon are given in [38]. The simulation results given in Figure 6 show a satisfactory rejection of the perturbations at the dc/dc converter output terminals, hence the stability and performance of the SMC under perturbations is verified. In conclusion, the performance of both the P\&O algorithm and SMC are validated by the results given in Figure 6, the PV voltage tracks the MPP of the PV source after the irradiance changes, and at the same time, perturbations imposed at the converter output terminals are rejected. Moreover, the simulations were performed for both step-down and step-up voltage operations since the converter output voltage reaches values lower and higher than the PV voltage.

\section{EXPERIMENTAL VALIDATION}

An experimental prototype was developed to validate the proposed solution. The prototype is formed by a PV source, a Ćuk power converter, the control stage and a DC bus; the circuital scheme of the prototype is 
depicted in Figure 7. The PV source is emulated using a $62050 \mathrm{H}-600 \mathrm{~S}$ PV emulator from CHROMA, which is configured with the characteristics of a BP585 PV panel. The DC link is emulated using a four quadrant electronic load BOP 50-20GL from KEPCO, which was configured in controlled voltage mode to emulate the perturbations imposed at the converter output terminals by a traditional grid-connected inverter. This proofof-concept platform includes an additional capacitor $C_{o}$ connected in parallel between the converter and the electronic load; such a capacitor is needed to avoid damages in the electronic load due to the high-frequency current ripple generated by the switching converter. However, the voltage of that capacitor is imposed by the electronic load, therefore it does not introduce an additional state and it is not considered into the mathematical and circuital analyses.

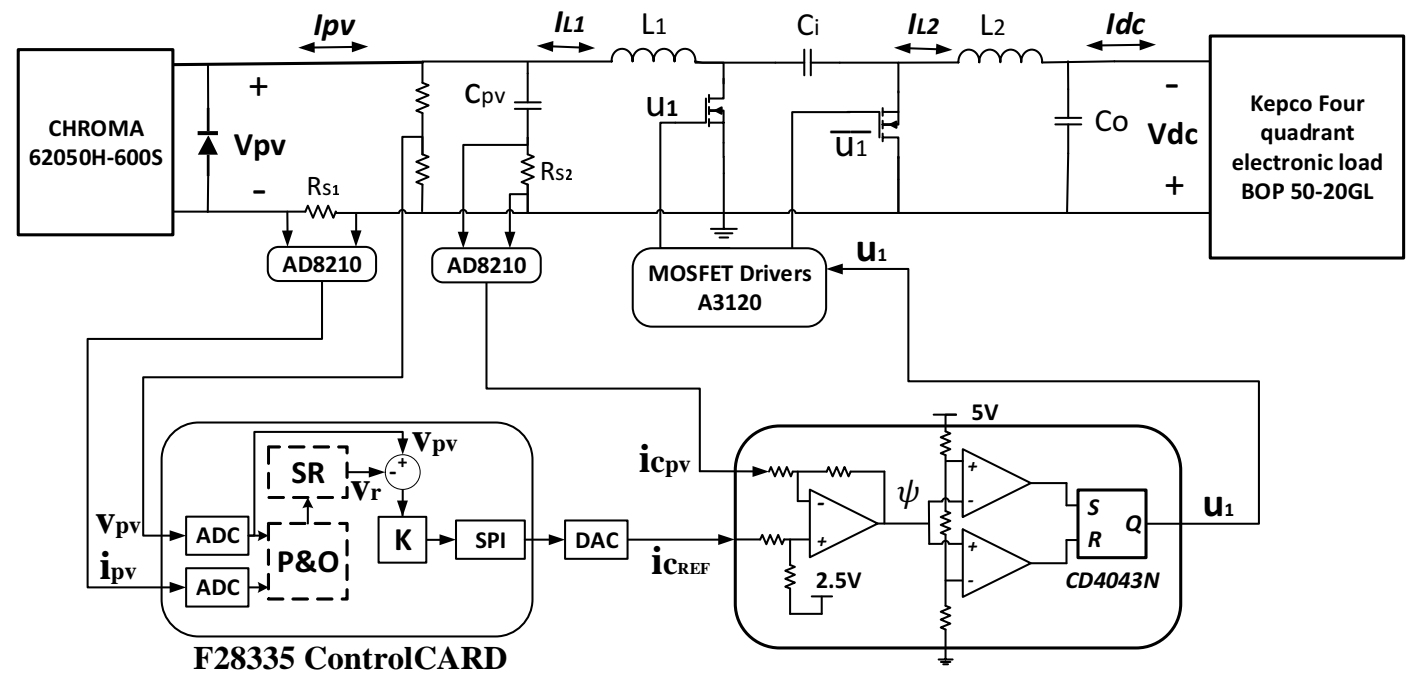

Figure 7. Circuital scheme of the experimental prototype

The elements used to construct the Ćuk converter were: $2318-V-R C$ inductors from Bourns Inc [47] with $L_{1}=330 \mu \mathrm{H}$; B32524R0476K000 capacitors from EPCOS AG [48] with $C_{p v}=C_{i}=C_{o}=22 \mu F$; IRF3710 MOSFETs from International rectifier [49]; and MOSFET drivers $A 3120$ from avago technology. PV current and capacitor current sensors were implemented with WSL12065L000FEA18 shunt-resistors from Vishay Dale [50], and using current shunt monitors $A D 8210$ from analog device [51] to provide a highbandwidth measurement. In addition, the PV voltage was measured using a voltage divider.

The control stage of the SMC was formed by both analog and digital components. The digital component was formed by a digital signal processor (DSP) F28335 controlCARD from Texas instrument [52], which has analog-to-digital converters (ADC) to acquire the PV voltage and current measurements, both necessary to process the MPPT algorithm and to calculate part of the switching function (13): inside the DSP the term $K \cdot\left(v_{p v}-v_{r}\right)$ is calculated. Finally, the $M P C 4822$ digital-to-analog converter (DAC), with SPI interface from microchip [53], was used provide this component of the switching function, as an analog value named $i_{C_{R e f}}$, to the analog stage.

The analog stage was using operational amplifiers to calculate the difference between the capacitor current and the switching function component $i_{C_{R e f}}$ generated by the digital stage, which produces the switching function $\psi$. This stage also generates the control action $u$ by using the integrated circuit $C D 4043 N$, two comparators and a set of resistors as it is presented in Figure 7. Finally, the SMC and MPPT parameters were the same ones adopted for the simulations. Figure 8 shows the experimental setup, which depicts the connection between the Ćuk converter, PV emulator, four quadrant electronic load, SMC and P\&O implementations.

Figure 9 shows the experimental measurements of the first test performed to the prototype, where the PV panel operates under a constant irradiance condition $\left(1000 \mathrm{~W} / \mathrm{m}^{2}\right)$ and a sinusoidal perturbation is imposed at the converter output terminals with a frequency of $120 \mathrm{~Hz}$, centered at $18 \mathrm{~V}$, and with a peak to peak amplitude of $6 \mathrm{~V}$. Under those conditions, the P\&O imposes a stable three-point profile to both the PV voltage $\left(v_{p v}\right)$ and current $\left(i_{p v}\right)$, which put into evidence the operation at the MPP. This is confirmed by the PV power 
$\left(p_{p v}\right)$ waveform, which is around $85 \mathrm{~W}$. Moreover, the experimental waveform of the switching function $\psi$ is always constrained into the hysteresis band $H$, which confirms the global stability of the power system, hence it confirms the correct tracking of the MPPT reference and the rejection of the perturbations introduced at the converter output terminals.

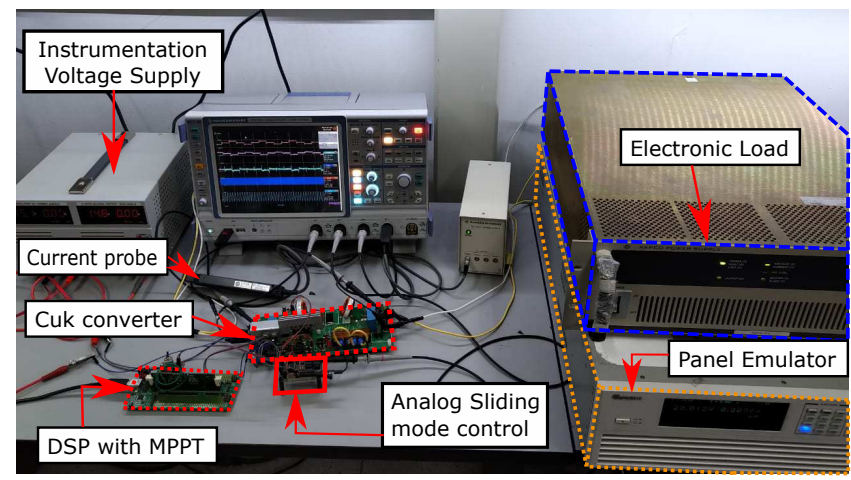

Figure 8. Experimental setup

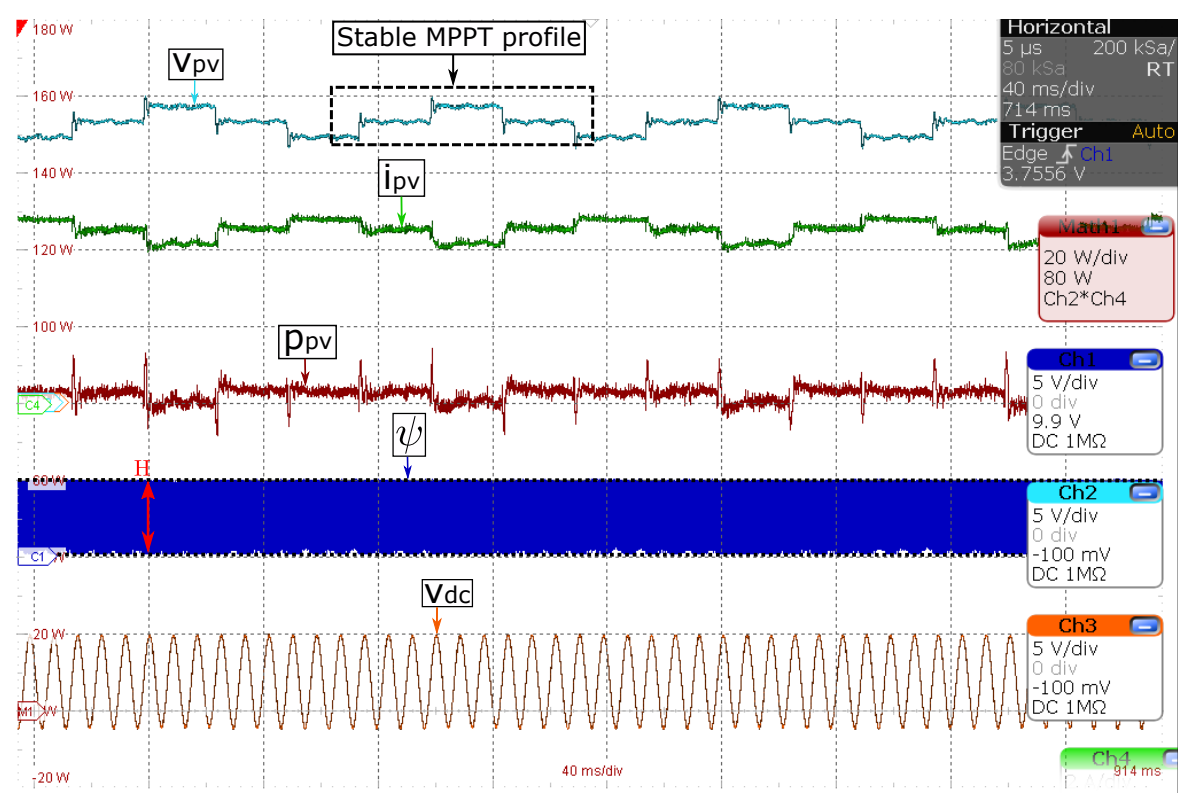

Figure 9. Experimental test at constant irradiance and output voltage perturbations

A second test was performed to evaluate the system performance to changes on the irradiance condition. Figure 10 reports the experimental results, where the $\mathrm{P} \& \mathrm{O}$ accurately tracks the MPP at all the irradiance conditions: the PV emulator starts operating at $1000 \mathrm{~W} / \mathrm{m}^{2}$, then the irradiance changes to $500 \mathrm{~W} / \mathrm{m}^{2}(50 \%$ step-down perturbation), and later returns to operate at $1000 \mathrm{~W} / \mathrm{m}^{2}$ (50\% step-up perturbation). The PV voltage is accurately regulated by the SMC, which is evident in the stable waveform at the moments when the irradiance changes. Similarly, the PV voltage and current waveforms converge to the MPP following the $\mathrm{P} \& \mathrm{O}$ command, which ensures a stable and optimal power production, as it is reported in the waveform of $p_{p v}$. Moreover, this experiment also considers the perturbation at the converter output terminals, which is observed in the $v_{d c}$ waveform. Finally, this experimental results are in agreement with the simulations reported in Figure 6. In conclusion, the experimental results reported in this section confirm the ability of the proposed PV system to interact with dc-links (or loads) requiring voltages lower, equal or higher than the PV voltage. Moreover, the designed SMC provides global stability under both environmental and load perturbations. 


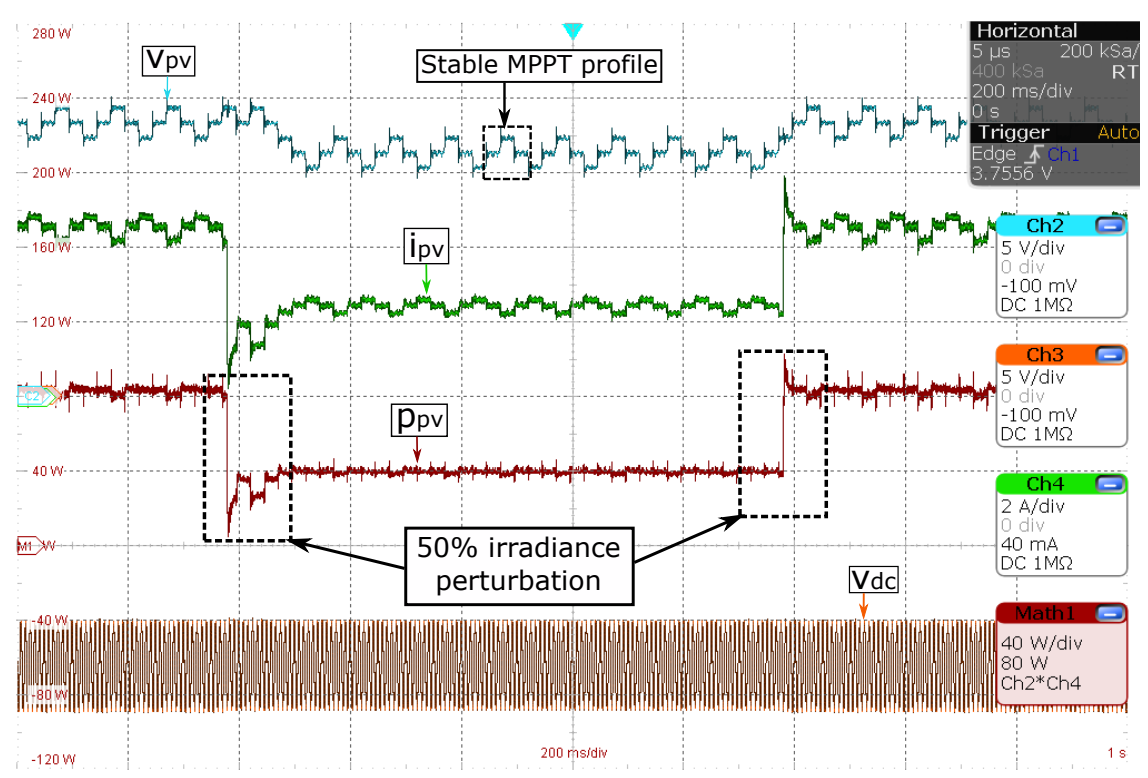

Figure 10. Experimental test with perturbations in both the irradiance and output voltage

\section{CONCLUSIONS}

A sliding mode controller for regulating dc/dc Ćuk converters in both classical and DMPPT PV systems has been designed and tested. The proposed switching function consists of a combination of the voltage error and the input capacitor current that ensures a stable and robust sliding regime when the dynamic restrictions on the reference voltage, provided by the MPPT algorithm, fulfills the limits calculated in the mathematical analysis. Simulated transient responses at different time scales verified the accurate dynamic response provided by the controller; in particular, the perturbations at twice the grid frequency that are usually found in two-stage grid-connected PV systems are completely mitigated. Moreover, an experimental proof-of-concept prototype was developed, which confirmed the applicability of the proposed solution for practical PV installations. The experiments also put into evidence that non-idealities such as losses and signal delays do not affect, significantly, the performance and stability of the proposed controller. A future improvement of this solution could be based on integrating into a single device all the controller parts; such an implementation will remove the need of costly DAC circuits. Such a digital implementation of the fast-switching SMC is a topic under development.

\section{ACKNOWLEDGMENTS}

This work was supported by the Instituto Tecnológico Metropolitano, Universidad Nacional de Colombia, Universitat Rovira i Virgili and Minciencias (Fondo nacional de financiamiento para ciencia, la tecnología y la innovación Francisco José de Caldas) under the project "Estrategia de transformación del sector energético Colombiano en el horizonte de 2030 - Energética 2030" - "Generación distribuida de energía eléctrica en Colombia a partir de energía solar y eólica" (Code: 58838, Hermes: 38945). The authors thank the Instituto Tecnológico Metropolitano for the payment of the article processing charges.

\section{REFERENCES}

[1] Solarinsure, "Top 5 Largest Solar Power Plants of the World,” Tech. Rep., 2019.

[2] A. Al-Badi, "Measured performance evaluation of a $1.4 \mathrm{~kW}$ grid connected desert type PV in Oman," Energy for Sustainable Development, vol. 47, pp. 107-113, dec 2018.

[3] S. S. Rashwan, A. M. Shaaban, and F. Al-Suliman, "A comparative study of a small-scale solar PV power plant in Saudi Arabia," Renewable and Sustainable Energy Reviews, vol. 80, pp. 313-318, dec 2017.

[4] E. De Schepper, S. Lizin, B. Durlinger, H. Azadi, and S. Van Passel, "Economic and Environmental 
Performances of Small-Scale Rural PV Solar Projects under the Clean Development Mechanism: The Case of Cambodia," Energies, vol. 8, no. 9, pp. 9892-9914, sep 2015.

[5] R. Dogga and M. Pathak, "Recent trends in solar PV inverter topologies," Solar Energy, vol. 183, pp. 57-73, may 2019.

[6] A. Elmelegi, M. Aly, E. M. Ahmed, and A. G. Alharbi, "A simplified phase-shift PWM-based feedforward distributed MPPT method for grid-connected cascaded PV inverters," Solar Energy, vol. 187, pp. 1-12, jul 2019.

[7] B. Gayathri Devi and B. Keshavan, "A novel hybrid Phase Shifted-Modified Synchronous Optimal Pulse Width Modulation based 27-level inverter for grid-connected PV system," Energy, vol. 178, pp. 309-317, jul 2019.

[8] G. Ertasgin, D. M. Whaley, N. Ertugrul, and W. L. Soong, "Analysis of DC Link Energy Storage for Single-Phase Grid-Connected PV Inverters,” Electronics, vol. 8, no. 6, p. 601, may 2019.

[9] J. Liu, J. Wu, J. Qiu, and J. Zeng, "Switched Z-Source/Quasi-Z-Source DC-DC Converters With Reduced Passive Components for Photovoltaic Systems," IEEE Access, vol. 7, pp. 40 893-40 903, 2019.

[10] I. F. Moran, J. A. Restrepo, M. L. Orozco-Gutierrez, and J. M. Ramirez-Scarpetta, "Quasi-switched inverter using space vector pulse width modulation with triangular comparison for photovoltaic applications," TecnoLogicas, vol. 21, no. 42, pp. 95-110, may 2018.

[11] H. Watanabe, J.-i. Itoh, N. Koike, and S. Nagai, "PV Micro-Inverter Topology Using LLC Resonant Converter," Energies, vol. 12, no. 16, p. 3106, aug 2019.

[12] S. M. Goetz, C. Wang, Z. Li, D. L. Murphy, and A. V. Peterchev, "Concept of a distributed photovoltaic multilevel inverter with cascaded double H-bridge topology," International Journal of Electrical Power and Energy Systems, vol. 110, pp. 667-678, sep 2019.

[13] G. Spagnuolo, E. Franco, J. D. Bastidas-Rodriguez, C. A. Ramos-Paja, and G. Petrone, "Maximum power point tracking architectures for photovoltaic systems in mismatching conditions: a review," IET Power Electronics, vol. 7, no. 6, pp. 1396-1413, jun 2014.

[14] J. D. Bastidas-Rodriguez, D. Gonzalez, S. Acevedo, and J. Pelaez-Restrepo, "Design and Control of a Buck-Boost Charger-Discharger for DC-Bus Regulation in Microgrids," Energies, vol. 10, no. 11, p. 1847, nov 2017.

[15] J. Lopez, S. Seleme, P.Donoso, L.Morais, P.Cortizo, and M. Severo, "Digital con-trol strategy for a buck converter operating as a battery charger for stand-alone pho-tovoltaic systems," Solar Energy, vol. 140, pp. 171-187, dec 2016.

[16] H.-S. Lee and J.-J. Yun, “Advanced MPPT Algorithm for Distributed Photovoltaic Systems,” Energies, vol. 12, no. 18, p. 3576, sep 2019.

[17] C. Ramos-Paja, et al., "Sliding-Mode Control of Distributed Maximum Power Point Tracking Converters Featuring Overvoltage Protection," Energies, vol. 11, no. 9, p. 2220, aug 2018.

[18] A. Amir, et al., "Application of modified classical numerical methods for DMPPT on Buck and Boost converters," Solar Energy, vol. 173, pp. 437-448, oct 2018.

[19] K. Tse, et al., "A novel maximum power point tracker for PV panels using switching frequency modulation,” IEEE Transactions on Power Electronics, vol. 17, no. 6, pp. 980-989, nov 2002.

[20] B. Chong and L. Zhang, "Controller design for integrated PV-converter modules under partial shading conditions," Solar Energy, vol. 92, pp. 123-138, jun 2013.

[21] R. Palanisamy, et al., "Simulation of various DC-DC converters for photovoltaic system," International Journal of Electrical and Computer Engineering (IJECE), vol. 9, no. 2, pp. 917-925, apr 2019.

[22] B. Isaloo and P. Amiri, "Improved variable step size incremental conductance MPPT method with high convergence speed for PV systems," Journal of Engineering Science and Technology, vol. 11, pp. 516$528,2016$.

[23] T. Radjai, L. Rahmani, S. Mekhilef, and J. P. Gaubert, "Implementation of a modified incremental conductance MPPT algorithm with direct control based on a fuzzy duty cycle change estimator using dSPACE," Solar Energy, vol. 110, pp. 325-337, dec 2014.

[24] E. Irmak and N. Guler, "Application of a high efficient voltage regulation system with MPPT algorithm," International Journal of Electrical Power and Energy Systems, vol. 44, no. 1, pp. 703-712, jan 2013.

[25] A. M. Othman, et al., "Realworld maximum power point tracking simulation of PV system based on Fuzzy Logic control," NRIAG J. of Astronomy and Geophysics, vol. 1, no. 2, pp. 186-194, dec 2012.

[26] A. Safari and S. Mekhilef, "Simulation and Hardware Implementation of Incremental Conductance MPPT 
With Direct Control Method Using Cuk Converter,' IEEE Transactions on Industrial Electronics, vol. 58, no. 4, pp. 1154-1161, apr 2011.

[27] J. C. d. S. de Morais, et al., "Photovoltaic AC Module Based on a Cuk Converter With a Switched-Inductor Structure," IEEE Transactions on Industrial Electronics, vol. 66, no. 5, pp. 3881-3890, may 2019

[28] W. M. Amutha, et al., "Renewable power interface based rural telecom," International Journal of Power Electronics and Drive Systems (IJPEDS), vol. 10, no. 2, pp. 917-927, jun 2019.

[29] N. Priyadarshi, et al., "An Ant Colony Optimized MPPT for Standalone Hybrid PV-Wind Power System with Single Cuk Converter," Energies, vol. 12, no. 1, p. 167, jan 2019.

[30] J. Knight, S. Shirsavar, and W. Holderbaum, "An improved reliability cuk based solar inverter with sliding mode control," IEEE Transactions on Power Electronics, vol. 21, no. 4, pp. 1107-1115, jul 2006.

[31] R. Kumar and B. Singh, "Solar PV powered BLDC motor drive for water pumping using Cuk converter," IET Electric Power Applications, vol. 11, no. 2, pp. 222-232, feb 2017.

[32] B. Singh, A. K. Mishra, and R. Kumar, "Solar powered water pumping system employing switched reluctance motor drive," 6th IEEE Power India International Conference (PIICON)., dec 2014, pp. 1-6.

[33] A. A. S. Mohamed, A. Berzoy, and O. A. Mohammed, "Design and hardware implementation of fl-mppt control of pv systems based on ga and small-signal analysis," IEEE Transactions on Sustainable Energy, vol. 8, no. 1, pp. 279-290, 2017.

[34] M. S. Ibbini and A. H. Adawi, "A SIMSCAPE based design of a dual maximum power point tracker of a stand-alone photovoltaic system," International Journal of Electrical and Computer Engineering (IJECE), vol. 10, no. 3, p. 2912, jun 2020.

[35] A. Diab-Marzouk and O. Trescases, "SiC-Based Bidirectional Cuk Converter With Differ- ential Power Processing and MPPT for a Solar Powered Aircraft," IEEE Transactions on Transportation Electrification, vol. 1, no. 4, pp. 369-381, dec 2015.

[36] M. Uno and A. Kukita, "Single-Switch Voltage Equalizer Using Multistacked Buck-Boost Converters for Partially Shaded Photovoltaic Modules," IEEE Transactions on Power Electronics, vol. 30, no. 6, pp. 3091-3105, jun 2015.

[37] H. G. Chiacchiarini, et al., "Cuk Converters for Balanced Power Extraction in Photovoltaic Panels," IEEE Latin America Transactions, vol. 14, no. 6, pp. 2611-2617, jun 2016.

[38] A. Darwish, et al., "A Single-Stage Three-Phase Inverter Based on Cuk Converters for PV Applications," IEEE Journal of Emerging and Selected Topics in Power Electronics, vol. 2, no. 4, pp. 797-807, dec 2014.

[39] E. Selwan, Z. Gajic, and G. Park, "Optimal control of the Cuk converter used in solar cells via a jump parameter technique," IET Control Theory and Applications, vol. 9, no. 6, pp. 893-899, apr 2015.

[40] L. Samani and R. Mirzaei, "Model predictive control method to achieve maximum power point tracking without additional sensors in stand-alone renewable energy systems," Optik, vol. 185, pp. 1189-1204, may 2019.

[41] E. Bianconi, et al., "Perturb and observe MPPT algorithm with a current controller based on the sliding mode," International Journal of Electrical Power and Energy Systems, vol. 44, no. 1, pp. 346-356, 2013.

[42] N. Femia, G. Petrone, G. Spagnuolo, and M. Vitelli, "A technique for improving p o mppt performances of double-stage grid-connected photovoltaic systems," IEEE Transactions on Industrial Electronics, vol. 56, no. 11, pp. 4473-4482, 2009.

[43] L. T. Phong and N. D. Minh, "Application of Sliding Mode Control Technique to Regulate DC/DC Boost Converters in Systems Exploiting Photovoltaic Power Generation," IAES International Journal of Robotics and Automation (IJRA), vol. 7, no. 2, p. 96, jun 2018.

[44] D. Gonzalez Montoya, C. A. Ramos Paja, and R. Giral, "Maximum power point track- ing of photovoltaic systems based on the sliding mode control of the module admittance," Electric Power Systems Research, vol. 136, pp. 125-134, jul 2016.

[45] R. W. Erickson and D. Maksimovic, "Fundamentals of Power Electronics," Boston, MA: Springer US, 2001.

[46] J. A. Cortajarena, O. Barambones, P. Alkorta, and J. De Marcos, "Sliding mode control of grid-tied single-phase inverter in a photovoltaic MPPT application," Solar Energy, vol. 155, pp. 793-804, oct 2017.

[47] Bourns, "High Current Toroid Inductors," Bourns, Tech. Rep., 2009.

[48] TDK, "Film Capacitors B32520... B32529," EPCOS AG, Tech. Rep.

[49] I. Rectifier, "Advanced HEXFET R Power MOSFETs from International Rectifier u," International Rectifier, California, USA, Tech. Rep., 2010. 
[50] Vishay, "Power Metal Strip R Resistors, High Power (2 x Standard WSL), Low Value (down to 0.001 ), Surface Mount," Vishay Intertechnology, Inc., Malvern, Pennsylvania, USA, Tech. Rep., 2008.

[51] A. Device, "High Voltage, Bidirectional Current Shunt Monitor," Analog Device, Norwood, Massachusetts,USA, Tech. Rep., 2017.

[52] T. I. Inc., "TMS320F2833x, TMS320F2823x Digital Signal Controllers (DSCs)," Texas Instruments Inc., Dallas, TX, USA, Tech. Rep., 2016.

[53] Microchip, "8/10/12-Bit Dual Voltage Output Digital-to-Analog Converter with Internal VREF and SPI Interface,” Microchip Technology Inc, Chandler, Arizona, USA, Tech. Rep., 2010.

\section{BIOGRAPHIES OF AUTHORS}

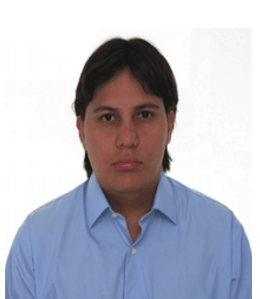

Carlos Andrés Ramos-Paja He was born in Cali, Colombia. He received the engineer degree in electronics from the Universidad del Valle-Colombia in 2003, a master degree on automatic control from the same university in 2005, and the Ph.D. degree in power electronics from the Universitat Rovira i Virgili-Spain in 2009. Since 2009 he has been Professor in the Universidad Nacional de Colombia, where since 2012 he is Associate Professor. His main research interests are in the design and control of renewable energy systems and microgrids, switching converters, distributed power systems and power quality solutions.

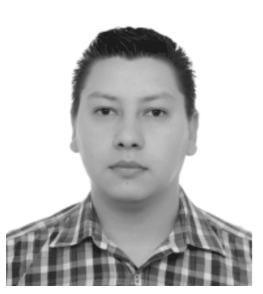

Daniel González-Motoya He was born in Medellin, Colombia. He received the engineer degree in control from the Universidad Nacional de Colombia in 2010, a master degree on industrial automatic from the same university in 2012, and the Ph.D. degree in automatic engineering from the Universidad Nacional de Colombia in 2017. Since 2015 he has Professor in the Instituto Tecnológico Metropolitano ITM. His main research interests are in the design control strategies of renewable energy systems and switching converters.

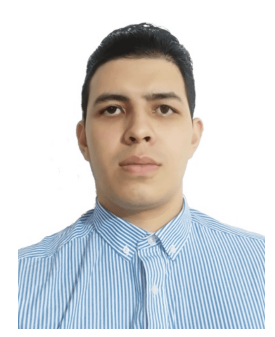

Juan Pablo Villegas-Ceballos He was born in Medellin, Colombia. He received the Electronic Engineer and Master Degree from Instituto Tecnologico Metropolitano of Colombia in 2014 and 2019, respectively. Currently, he is a Professor in Department of Electronics and Telecommunications at Instituto Tecnológico Metropolitano, Colombia. His research interest includes Smart Grids, Energy Storage Systems, Norlinear Control and Optimization techniques for electric systems.

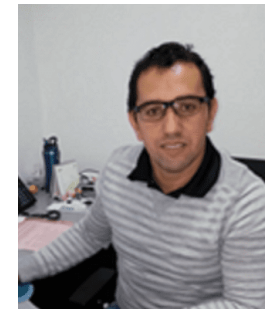

Sergio Ignacio Serna-Garcés He was born in Medellín, Colombia, in 1971. He received the engineer degree in electrical from the Universidad Nacional de Colombia in 1998, and electronics from the Universidad de Antioquia in 2005, a master degree on system engineering from the Universidad Nacional de Colombia in 2011, and the degree of Doctor of Engineering - Automatic Engineering from the same University in 2019. Since 2015 he has been Professor in the Instituto Tecnológico Metropolitano in Medellín-Colombia, where since 2019 he is Assistant Professor. His main research interests are in DC/DC switching converter design, the design and control of renewable energy systems, and embedded systems.

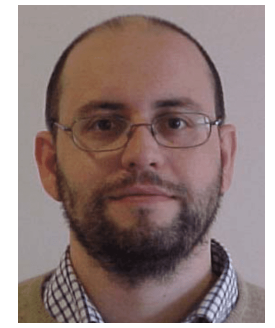

Roberto Giral Received the B.S. degree in ingenieria tecnica de telecomunicacion, the M.S. degree in ingenieria de telecomunicacion, and the Ph.D. (with Hons.) degree from the Universitat Politecnica de Catalunya, Barcelona, Spain, in 1991, 1994, and 1999, respectively. He is currently an Associate Professor with the Departament dEnginyeria Electronica, Electrica i Automatica, Escola Tecnica Superior dEnginyeria, Universitat Rovira i Virgili, Tarragona, Spain, where he is working in the field of power electronics.

Int J Elec \& Comp Eng, Vol. 11, No. 3, June $2021: 2027$ - 2044 